\title{
The relationship between cough-specific quality of life and abdominal muscle endurance, fatigue, and depression in patients with COPD
}

This article was published in the following Dove Press journal:

International Journal of COPD

7 September 2015

Number of times this article has been viewed

\author{
Hulya Arikan' \\ Sema Savci² \\ Ebru Calik-Kutukcu' \\ Naciye Vardar-Yagli' \\ Melda Saglam' \\ Deniz Inal-Ince' \\ Lutfi Coplu ${ }^{3}$
}

'Department of Physiotherapy and Rehabilitation, Faculty of Health Sciences, Hacettepe University, Ankara, Turkey; ${ }^{2} \mathrm{School}$ of

Physiotherapy and Rehabilitation, Dokuz Eylul University, Izmir, Turkey;

${ }^{3}$ Department of Chest Medicine, Faculty of Medicine, Hacettepe University, Ankara, Turkey
Correspondence: Ebru Calik-Kutukcu Department of Physiotherapy and Rehabilitation, Faculty of Health Sciences, Hacettepe University, 06 I00 Samanpazari, Ankara, Turkey

Tel +903 I 2305 I577 extension I78

$\mathrm{Fax}+903123052012$

Email ebrucalk85@hotmail.com
Background: Cough is a prevalent symptom that impacts quality of life in COPD. The aim of this study was to assess the relationship between cough-specific quality of life, abdominal muscle endurance, fatigue, and depression in stable patients with COPD.

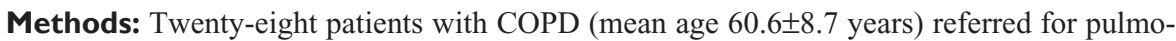
nary rehabilitation participated in this cross-sectional study. Sit-ups test was used for assessing abdominal muscle endurance. Leicester Cough Questionnare (LCQ) was used to evaluate symptom-specific quality of life. Fatigue perception was evaluated with Fatigue Impact Scale (FIS). Beck Depression Inventory (BDI) was used for assessing depression level.

Results: The LCQ total score was significantly associated with number of sit-ups; BDI score; FIS total; physical, cognitive, and psychosocial scores $(P<0.05)$. Scores of the LCQ physical, social, and psychological domains were also significantly related with number of sit-ups, FIS total score, and BDI score $(P<0.05)$. FIS total score and number of sit-ups explained $58 \%$ of the variance in LCQ total score $\left(r=0.76, r^{2}=0.577, F(2-20)=12.296, P<0.001\right)$.

Conclusion: Chronic cough may adversely affect performance in daily life due to its negative effect on fatigue and decrease abdominal muscle endurance in patients with COPD. Decreased cough-related quality of life is related with increased level of depression in COPD patients. Effects of increased abdominal muscle endurance and decreased fatigue in COPD patients with chronic cough need further investigation.

Keywords: cough, quality of life, depression, fatigue, chronic obstructive pulmonary disease

\section{Introduction}

COPD is characterized by persistent airflow limitation that is usually progressive and associated with an enhanced chronic inflammatory response to noxious particles and gases in the airways and lungs. The characteristic symptoms of COPD are chronic and progressive dyspnea, cough, and sputum production that can be variable from day to day. Initially, the cough may be intermittant, but later is present everyday, often throughout the day. ${ }^{1}$

While cough is an important defence mechanism that helps clear excessive secretions and foreign material from the airways, chronic cough was found to be significantly associated with meaningful adverse psychosocial and physical effects on health-related quality of life (HRQoL). ${ }^{2,3}$ Decrease in HRQoL with chronic cough was more likely to be psychosocial than physical in nature. ${ }^{2}$

There is now better evidence for the fact that people who have cough regularly, productive of sputum, are more likely to develop pneumonic complications during COPD exacerbations and subsequently die. ${ }^{4}$ Chronic cough defined as cough 
lasting $>8$ weeks causes significant morbidity and utilization of health care resources. ${ }^{5}$

Cough-related syncope, incontinence, vomiting, sleep deprivation, and depression are among some of the more severe adverse effects of cough and require prompt assessment and treatment. ${ }^{6,7}$ It was found that depressive symptomatology is very common in patients with chronic cough. ${ }^{8,9}$ Whereas abdominal muscle strength is preserved in stable COPD patients, ${ }^{10}$ it was shown that expiratory muscle endurance that primarily includes abdominal muscles is decreased in COPD. ${ }^{11}$ Fatigue is found to be significantly increased in COPD patients compared to controls, ${ }^{12,13}$ and dyspnea and physical symptoms have more impact on fatigue than physiologic variables. ${ }^{14}$ Prolonged coughing can cause soreness or even strain in the abdominal or rib muscles, and hence have a negative impact on abdominal muscle endurance. Inefficient use of abdominal muscles during cough may increase physical complaints and the patients' fatigue perception.

Although there are studies about the impact of cough on HRQoL in COPD compared with different diseases ${ }^{15}$ and healthy controls, ${ }^{16}$ we did not find any studies about the relationship between cough-specific quality of life and abdominal muscle endurance, fatigue, and depression in COPD. Therefore, the primary objective of the study was to investigate the relationship between cough-specific quality of life and abdominal muscle endurance, fatigue, and depression in patients with COPD. The secondary objective of the study was to identify which of these factors (abdominal muscle endurance, fatigue, and depression) influence cough-specific quality of life.

\section{Methods}

\section{Subjects}

This cros-sectional study included 28 COPD patients referred for pulmonary rehabilitation between the ages of 40 and 80 years (22 male/6 female, mean forced expiratory volume in 1 second $\left(\mathrm{FEV}_{1}\right): 53.7 \% \pm 24.9 \%$ ) who had been on the same medicine in the previous 3 weeks and not taking antibiotics. Patients who were not able to walk or who have a disability preventing them from walking, and patients who were not able to cooperate with pulmonary function tests and questionnares were not included in the study. The study was approved by the Ethical Committee of Hacettepe University and each subject signed an informed consent form.

\section{Assessments}

Physical, physiological, and sociodemographic data were recorded. Body mass index (BMI) was calculated with the formula body weight/height in meters ${ }^{2}\left(\mathrm{~kg} / \mathrm{m}^{2}\right) .{ }^{17}$ The patients' smoking history was recorded as pack-years. Dyspnea, cough, and sputum symptoms of patients were questioned and recorded. The number of exacerbations in the previous year before participating in this study was recorded. Patients' dyspnea levels were determined with the Modified Medical Research Council (MMRC) Dyspnea Scale. ${ }^{18}$

The pulmonary function test was performed with a Spirolab III spirometer (Spirolab; Medical International Research, Rome, Italy) according to the American Thoracic Society/European Respiratory Society criteria. Forced vital capacity (FVC), $\mathrm{FEV}_{1}, \mathrm{FEV}_{1} / \mathrm{FVC}$ rate, peak expiratory flow (PEF), and forced expiratory flow between $25 \%$ and $75 \%$ of FVC ( $\left.\mathrm{FEF}_{25 \%-75 \%}\right)$ were recorded. Pulmonary function test parameters were expressed as percentage of the expected value for age, height, body weight, and sex. ${ }^{19,20}$

Abdominal muscle endurance was assessed using a sit-ups test. Patients were asked to lift up the trunk from the supine position until the lower angle of the scapula with the arms stretched forward consecutively as quickly as possible for 30 seconds. Pressure was given on patients' knees with therapist's hands to hold the patients' feet on the ground. Verbal encouragement was given during test like "You are doing well. Continue". The number of sit-ups were recorded for analysis. ${ }^{21}$

The Leicester Cough Questionnaire (LCQ) is a valid and reliable health-related quality of life measurements for adults with chronic cough and patients with COPD. Adaptation of the LCQ was made for the Turkish people and Turkish version of the LCQ was used for evaluation. ${ }^{22}$ It consists a total of 19 items that are divided into physical (eight items), psychosocial (seven items), and social (four items) subdimensions. Total score ranges from 3 to 21 . Low scores on the LCQ means a higher effect of coughing on the subject. ${ }^{22,23}$

The fatigue perception of the subjects was evaluated by the Fatigue Impact Scale (FIS). FIS is a multidimensional scale to assess the patient's perception of the limitations in the physical (ten items), cognitive (ten items), and psychosocial (20 items) functions caused by fatigue during the last month. Total score ranges between 0 and 160 . High scores represents a higher effect of fatigue. ${ }^{24}$

Beck Depression Inventory (BDI) is a self-rating scale that has been developed to determine the risk of depression, level, and severity of depressive symptoms in individuals and is practiced in healthy subjects and psychiatric patients. It contains 21 self-assessment sentences. Each item is scored from 0 to 3 and total score is obtained by collecting them. The total score ranges from 0 to 63 . A score of $0-9$ indicates minimal depressive symptoms, 10-16 mild depressive 
symptoms, 17-29 moderate depressive symptoms, and 30-63 severe depressive symptoms. ${ }^{25}$

\section{Statistical analysis}

All the analyses were performed using the Statistical Program for the Social Sciences version 15.0 (SPSS Inc., Chicago, IL, USA) for Windows. ${ }^{26}$ Variables were expressed as mean \pm standard deviation, frequency, percentage, median, minimum, and maximum. Normal distribution of variables was tested with Shapiro-Wilk Test. Correlations were analyzed using the Pearson's correlation analysis because parametric conditions were met by the data. Correlations were classed as "high" $(r>0.70)$, "moderate" ( $r=0.50-0.69)$, "low" $(r=0.26-0.49)$, and "little or no correlation" ( $r=0.00-0.25) .{ }^{27}$ Multiple regression analysis was carried out using the LCQ total score as dependent variable and variables with a significant relationship with the LCQ total score $(P<0.015)$ based on correlation analysis as independent variable. With a 5\% type-1 error level and a total of 28 subjects, the study has $80 \%$ power to detect correlations with a magnitude of $|r|>0.45$ among the study parameters as statistically significant. The level of significance was set to $P<0.05{ }^{28}$

\section{Results}

Twenty-eight clinically stable patients with COPD were included in the study. Data regarding the characteristics of the participants are presented in Table 1. Mean age of the subjects was $60.6 \pm 8.7$ years and mean BMI was $27.1 \pm 5.5 \mathrm{~kg} / \mathrm{m}^{2}$. Mean $\mathrm{FEV}_{1}(\%)$ of COPD patients was $53.7 \% \pm 24.9 \%$. Approximately, $17.9 \%$ of the patients were in GOLD stage I, $35.7 \%$ in GOLD stage II, $25.0 \%$ in GOLD stage III, and

Table I Characteristics of COPD patients

\begin{tabular}{|c|c|}
\hline Variable & Mean \pm SD \\
\hline Age (years) & $60.6 \pm 8.7$ \\
\hline Sex (male/female) & $22 / 6$ \\
\hline Height (cm) & $166.4 \pm 8.4$ \\
\hline Body weight (kg) & $75.3 \pm 17.6$ \\
\hline Body mass index $\left(\mathrm{kg} / \mathrm{m}^{2}\right)$ & $27.1 \pm 5.5$ \\
\hline $\mathrm{FEV}_{1}(\%)$ & $53.7 \pm 24.9$ \\
\hline FVC (\%) & $69.9 \pm 10.6$ \\
\hline FEV,/FVC (\%) & $59.3 \pm 15.1$ \\
\hline $\mathrm{FEF}_{25 \%-75 \%}(\%)$ & $33.0 \pm 21.7$ \\
\hline PEF (\%) & $58.3 \pm 25.5$ \\
\hline \multirow[t]{2}{*}{ Smoking history (pack-years) } & $40.2 \pm 30.8$ \\
\hline & Median (minimum-maximum) \\
\hline Number of exacerbations (n) & $0(0-2)$ \\
\hline MMRC (0-4) & $\mathrm{I} .5(0-3)$ \\
\hline
\end{tabular}

Abbreviations: $\mathrm{FEV}_{1}$, forced expiratory volume in I second; FVC, forced vital capacity; $\mathrm{FEF}_{25 \%-75 \%}$, forced expiratory flow between $25 \%$ and $75 \%$ of FVC; PEF, peak expiratory flow; MMRC, Modified Medical Research Council Dyspnea Scale; $\mathrm{SD}$, standard deviation.
Table 2 Abdominal muscle endurance, cough-specific quality of life, fatigue perception, and depression level in patients with COPD

\begin{tabular}{ll}
\hline Variable & Mean \pm SD \\
\hline Number of sit-ups $(\mathrm{n})$ & $17.0 \pm 5.7$ \\
LCQ-total score (3-2I) & $15.9 \pm 3.8$ \\
Physical score & $5.2 \pm 1.2$ \\
Social score & $5.6 \pm 1.6$ \\
Psychological score & $5.1 \pm 1.2$ \\
FIS-total score (0-160) & $40.0 \pm 30.7$ \\
Physical score & $11.4 \pm 9.4$ \\
Cognitive score & $8.7 \pm 7.4$ \\
Psychosocial score & $19.5 \pm 14.5$ \\
BDI score (0-63) & $12.0 \pm 9.4$ \\
\hline
\end{tabular}

Abbreviations: LCQ, Leicester Cough Questionnaire; FIS, Fatigue Impact Scale; BDI, Beck Depression Inventory; SD, stansard deviation.

21.4\% in GOLD stage IV. Approximately, 64.3\% $(n=18)$ of patients had chronic cough and $96.4 \%$ of subjects had dyspnea symptom, and median of MMRC scores was 1.5.

Abdominal muscle endurance, cough-specific quality of life, fatigue perception, and depression level results are given in Table 2. Mean number of sit-ups was 17.0土5.7. Mean LCQ total score was $15.9 \pm 3.8$, mean FIS total score was 40.0 \pm 30.7 ,

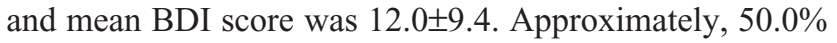
of patients had minimal depressive symptoms, $19.2 \%$ had mild depressive symptoms, $23.1 \%$ had moderate depressive symptoms, and $7.7 \%$ had severe depressive symptoms.

The LCQ total score was significantly correlated with number of sit-ups ( $r=0.704, P<0.001$, Figure 1), BDI score $(r=-0.550, P=0.004$, Figure 2$)$, FIS total $(r=-0.557, P=0.003$, Figure 3), physical ( $r=-0.543, P=0.003)$, cognitive ( $r=-0.494$, $P=0.009)$, and psychosocial scores $(r=-0.566, P=0.002)$. The LCQ physical score was also significantly related to the number of sit-ups ( $r=0.713, P<0.001)$, FIS total score $(r=-0.578$, $P=0.002)$, and BDI score $(r=-0.553, P=0.003)$. The LCQ

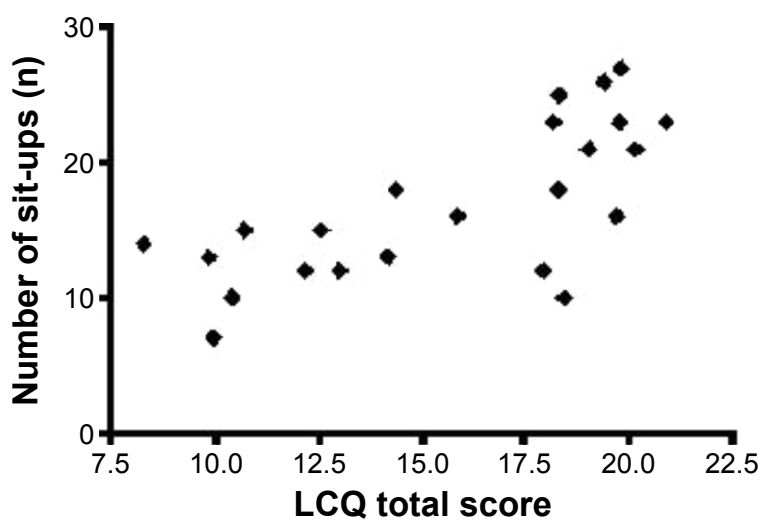

Figure I The relationship between cough-specific quality of life and abdominal muscle endurance.

Abbreviation: LCQ, Leicester Cough Questionnaire. 


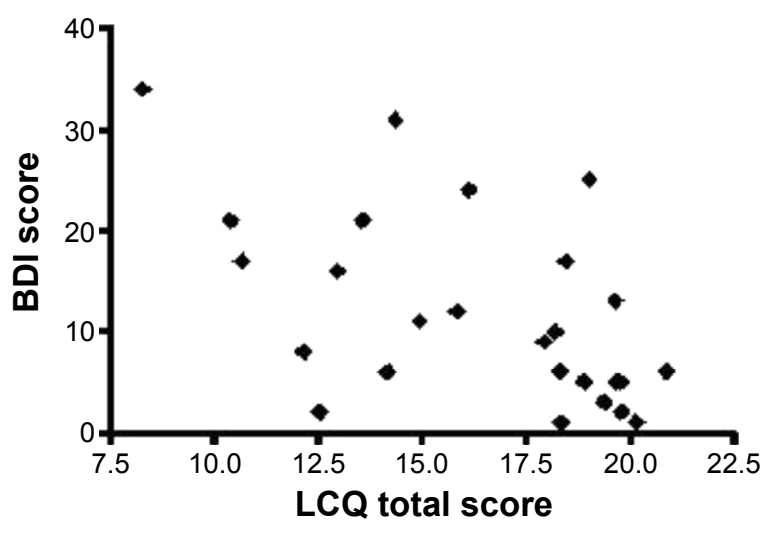

Figure 2 The relationship between cough-specific quality of life and depression level. Abbreviations: LCQ, Leicester Cough Questionnaire; BDI, Beck Depression Inventory.

social score was also significantly associated with the number of sit-ups ( $r=0.644, P=0.001)$, FIS total score $(r=-0.444$, $P=0.020)$, and BDI score $(r=-0.475, P=0.014)$. The LCQ psychological score was also significantly correlated with the number of sit-ups $(r=0.687, P<0.001)$, FIS total score ( $r=-0.602, P=0.001)$, and BDI score $(r=-0.552, P=0.003)$ (Table 3 ). Based on the multiple linear regression analysis, it was found that the FIS total score and number of sit-ups explained $58 \%$ of the variance in LCQ total score $(r=0.76$, $r^{2}=0.577, F(2-20)=12.296, P<0.001$, Table 4).

\section{Discussion}

In the present study, we have shown that lower cough-specific quality of life is associated with worse performance in daily living activities due to its negative effect on fatigue and lower abdominal muscle endurance, and higher depression levels are usually observed in patients with COPD. Besides, it was shown that the general impact of fatigue in daily

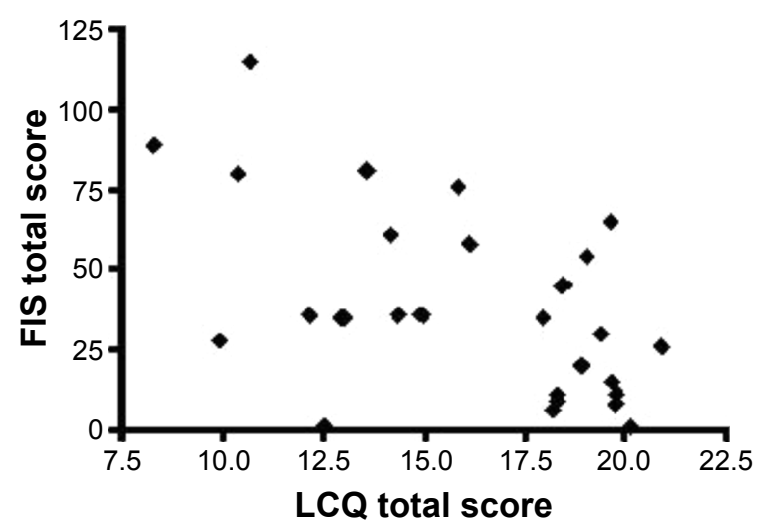

Figure 3 The relationship between cough-specific quality of life and general impact of fatigue on daily living activities.

Abbreviations: LCQ, Leicester Cough Questionnaire; FIS, Fatigue Impact Scale. life and abdominal muscle endurance may provide general information about the cough-specific quality of life.

While it is known that patients with chronic cough have a risk of physical complications, patients were found to be widely disturbed from psychosocial complications and combination of these side effects. Most of the patients with persistent cough suspect suffering from a serious condition (72\%), and they consult a physician to get assurance that they do not have such a condition (77\%). Rib fractures, incontinence, fatigue, shame, unconsciousness, difficult conversations on the phone, hoarse sound, inability to sleep at night, unable to stand close to the their relatives due to cough, and inability to work in school or elsewhere are the other complaints that may impair the quality of life. . $^{2,29}$ In the literature, it was shown that cough adversely affects health status in patients with COPD. ${ }^{15,16}$ In a study that comprised 54 patients with

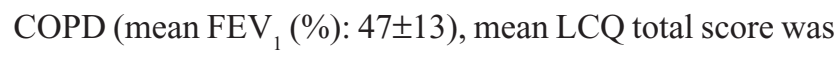
$13.6 \pm 2.8 .{ }^{23}$ In a group of COPD patients (mean $\mathrm{FEV}_{1}(\%)$ : 53.7 \pm 24.9 ) in our study, mean LCQ total score was $15.9 \pm 3.8$. In our study, we have shown that cough impairs HRQoL in a group of COPD patients with chronic cough (64.3\%), as reported in the literature..$^{15,16,23}$

Typical cough consists of four phases: inspiratory, compressive, expulsive, and relaxation phases. ${ }^{31}$ Coughing involves coordinated contractions of the thoracic, abdominal, and pelvic muscles. ${ }^{32}$ Abdominal muscles play an important role in expulsive phase. ${ }^{31}$ Abdominal muscle endurance of patients with COPD was shown to be lower than that of the healthy subjects. ${ }^{11,16}$ According to the SAFE index score, which is a multidimensional staging system for COPD, HRQoL evaluation is significantly related to the number of sit-ups in moderate to very severe COPD patients. ${ }^{33}$ In accordance with this finding, we determined that cough-specific quality of life is significantly related to abdominal muscle endurance. Because of the contraction of abdominal muscles during coughing, decrease in the endurance of these muscles may adversely affect cough efficiency and secretion clearance. Therefore, it may impair cough-specific quality of life by creating physical, social, and psychological problems.

According to previous studies, fatigue perception was found to be increased in patients with COPD compared to healthy subjects. ${ }^{16,34,35}$ It was shown that $95.3 \%$ of pulmonary rehabilitation participants with COPD (mean $\mathrm{FEV}_{1}(\%)$ : 47.8 \pm 16.3 ) experienced high levels of physical fatigue. ${ }^{36}$ In our previous study, we showed that $59 \%$ of the COPD patients aged 52-74 years had severe fatigue and their HRQoL scores, which were evaluated with St George's Respiratory Questionnaire, were significantly higher. ${ }^{33}$ Dyspnea, cough, 
Table 3 The correlations between cough-specific quality of life and abdominal muscle endurance, fatigue perception, and depression level in patients with COPD

\begin{tabular}{|c|c|c|c|c|c|c|}
\hline & $\begin{array}{l}\text { Number } \\
\text { of sit-ups }\end{array}$ & $\begin{array}{l}\text { FIS-physical } \\
\text { score }\end{array}$ & $\begin{array}{l}\text { FIS-cognitive } \\
\text { score }\end{array}$ & $\begin{array}{l}\text { FIS-psychosocial } \\
\text { score }\end{array}$ & $\begin{array}{l}\text { FIS-total } \\
\text { score }\end{array}$ & $\begin{array}{l}\text { BDI } \\
\text { score }\end{array}$ \\
\hline \multirow[t]{2}{*}{ The LCQ-physical score } & $r=0.713$ & - & - & - & $r=-0.578$ & $r=-0.553$ \\
\hline & $P<0.001$ & & & & $P=0.002$ & $P=0.003$ \\
\hline \multirow[t]{2}{*}{ The LCQ-social score } & $r=0.644$ & - & - & - & $r=-0.444$ & $r=-0.475$ \\
\hline & $P=0.001$ & & & & $P=0.020$ & $P=0.014$ \\
\hline \multirow[t]{2}{*}{ The LCQ-psychological score } & $r=0.687$ & - & - & - & $r=-0.602$ & $r=-0.552$ \\
\hline & $P<0.001$ & & & & $P=0.001$ & $P=0.003$ \\
\hline \multirow[t]{2}{*}{ The LCQ-total score } & $r=0.704$ & $r=-0.543$ & $r=-0.494$ & $r=-0.566$ & $r=-0.557$ & $r=-0.550$ \\
\hline & $P<0.001$ & $P=0.003$ & $P=0.009$ & $P=0.002$ & $P=0.003$ & $P=0.004$ \\
\hline
\end{tabular}

Abbreviations: LCQ, Leicester Cough Questionnaire; FIS, Fatigue Impact Scale; BDI, Beck Depression Inventory.

and lack of energy were found to be the most prevalent symptoms in patients with COPD. ${ }^{13}$ In a study that comprised 564 subjects with COPD, fatigue was found to be affected by respiratory symptoms and concomitant heart disease. In stage $\geq$ II COPD patients with respiratory symptoms (MMRC dyspnea score $\geq 2$, chronic cough, chronic productive cough, or recurrent wheeze), there was an increased risk for clinically significant fatigue. ${ }^{37}$ Increase in fatigue in COPD patients was found to be related to reduced time spent outdoors, and increase in depression and annual exacerbation frequency. ${ }^{12} \mathrm{In}$ a cross-sectional study with 130 moderate to severe patients with COPD, a strong relationship was found between fatigue and dyspnea. Dyspnea, depressed mood, and sleep quality explained $42 \%$ of the variance in subjective fatigue. ${ }^{38}$ Because COPD exacerbations are episodes of sustained deterioration in respiratory symptoms due to increased systemic inflammation, ${ }^{39}$ increase in cough severity and frequency in these exacerbation periods may decrease cough-specific quality of life and increase general impact of fatigue in physical, cognitive, and psychosocial daily life activities. In our study, increase in dyspnea and cough symptoms during exacerbation periods of patients who have maximum two exacerbations in 1 year, depressed mood, and adverse effects of chronic cough can explain relationship between fatigue perception and cough-specific quality of life. Similar to other studies in

Table 4 Multiple linear regression analysis

\begin{tabular}{lcclll}
\hline & $\boldsymbol{R}$ & $\boldsymbol{R}^{2}$ & $\begin{array}{l}\text { Univariate } \\
\text { analysis }\end{array}$ & $\mathbf{B}$ & $\boldsymbol{\beta}$ \\
\hline FIS total score & 0.667 & 0.444 & 0.444 & 19.213 & -0.667 \\
Number of sit-ups & 0.760 & 0.577 & 0.133 & 13.008 & 0.424 \\
$R^{2}=0.577, F_{(2-2)}=12.296, P<0.001$, constant $=289.007$ & & \\
\hline
\end{tabular}

Notes: Dependent variable: LCQ total score; independent variables (if $P \leq 0.015$ ): number of sit-ups, BDI score, FIS total score, FIS physical score, FIS cognitive score, and FIS psychosocial score.

Abbreviations: LCQ, Leicester Cough Questionnaire; FIS, Fatigue Impact Scale; BDI, Beck Depression Inventory. the literature, we have found a relationship between general fatigue and HRQoL. ${ }^{40,41}$ To the authors' knowledge, this is the first study that determines the relation between fatigue perception and cough-specific quality of life.

In a study comprising 57 patients with chronic cough, $33 \%$ were identified as anxious while $16 \%$ experienced depression. Approximately, $48 \%$ of all coughers had moderate or high trait anxiety. In addition, patients' mean scores on the phobic anxiety, somatization, depression, and obsession subscales were significantly higher than the published mean scores for healthy controls. ${ }^{9}$ In $53 \%$ of the patient group consulting a specialty center for seeking evaluation and treatment of chronic cough, significant depressive symptoms and risk for clinical depression were shown. There was a statistically significant improvement in both cough severity and depression scores after 3 months among subjects followed up at 3 months. Improvement in cough score was found to be correlated significantly with improvement in depression score. ${ }^{8}$ In another study population, $33.3 \%$ of COPD patients showed moderate to severe depressive symptoms. In addition, educational and occupational status, $\mathrm{BMI}, \mathrm{FEV}_{1}$, respiratory symptoms, physical impairment, and dyspnea were found to be potential predictors of depression in COPD patients. ${ }^{42}$ Depression and anxiety were significantly correlated with HRQoL at 1-year follow-up in a meta-analysis with six studies. ${ }^{43}$ In our study, we found significant relationship between depression level and effects of cough on physical, social, and psychological subdimensions and general quality of life. Our findings in the study population, $32 \%$ of whom had moderate to severe depression level, are consistent with literature that reports high prevalence of depressive symptoms in patients with chronic cough and relationship between depression and HRQoL. ${ }^{8,9,42,43}$

We also found that the FIS total score and the number of sit-ups explain $58 \%$ of the variance in the LCQ total score. 
These findings suggest the important roles of general impact of fatigue on daily life and abdominal muscle endurance on overall cough-specific quality of life. To evaluate the impact of cough on patients and to assess the efficacy of cough treatments, investigators should use both subjective and objective methods because they have the potential to measure different aspects of cough. Subjective measures such as HRQoL instruments are likely to best reflect the severity of cough from the patient's standpoint because a subjective response most likely integrates both cough frequency and intensity. ${ }^{30,44}$ Quality of life measures can be used to facilitate communication with patients and establish information regarding the range of problems affecting them. The impact of illness on health and treatment preferences often differ between patient and physician, and, therefore, quality of life considerations should take the patient's perspective into account. ${ }^{30}$ The LCQ is a brief, easy to administer, and well-validated chronic cough HRQoL questionnaire developed in the $\mathrm{UK}^{45}$ and validated for Turkish population. ${ }^{22}$

\section{Limitations}

There are several limitations to this study. The sampling was not strong enough to support the conclusions. In addition, fatigue perception questionnaire was not disease-specific.

\section{Conclusion}

In conclusion, this study showed that worse cough-specific quality of life is associated with lower abdominal muscle endurance; higher fatigue impact on physical, cognitive, and psychosocial activities; and higher depression level. Chronic cough can have profound effects on quality of life. Its management should include an assessment of health status. In the clinic of chest diseases and pulmonary rehabilitation programs, the LCQ can be used to assess longitudinal changes and identify the specific health domains affected in patients with COPD. ${ }^{46}$ If cough is an important part of COPD and contributes to deterioration in quality of life, the symptom should be controlled. ${ }^{4}$ Successful treatment of chronic cough was found to be associated with resolution of patients' deterioration in HRQoL., ${ }^{3,47} \mathrm{We}$ found in our study that the general impact of fatigue in daily life and abdominal muscle endurance may provide general information about the cough-specific quality of life. Using these FIS questionnares for fatigue perception and the sit-ups test for abdominal muscle endurance for the evaluation of patients with COPD with chronic cough can give us general idea about the patients' quality of life and give rehabilitation professionals the opportunity to select the most appropriate therapeutic applications in the rehabilitative management of COPD patients.

Further work is required to determine the effects of pulmonary rehabilitation interventions on increasing abdominal muscle endurance and decreasing fatigue in COPD patients with chronic cough.

\section{Acknowledgment}

The authors thank Fusun Kalpaklioglu from Kirikkale University, Faculty of Medicine, Department of Allergy, Ankara, Turkey, for her permission to use Turkish version of Leicester Cough Questionnaire.

\section{Disclosure}

The authors have no financial disclosures to declare and no conflicts of interest to report.

\section{References}

1. Goldcopd.org. Global Initiative for Chronic Obstructive Lung Disease (GOLD). Global strategy for the diagnosis, management and prevention of chronic obstructive pulmonary disease. Available from: http://www. goldcopd.org. Accessed April 10, 2015.

2. French CL, Irwin RS, Curley FJ, Krikorian CJ. Impact of chronic cough on quality of life. Arch Intern Med. 1998;158:1657-1661.

3. French CT, Irwin RS, Fletcher KE, Adams TM. Evaluation of a coughspecific quality-of life questionnaire. Chest. 2002;121:1123-1131.

4. Chung KF, Calverley PMA. Cough in chronic obstructive pulmonary disease. In: Chung M, Widdicombe J, Boushey H, editors. Cough: Causes, Mechanisms and Therapy. 1st United States of America: Blackwell Publishing; 2003:125-135.

5. Morice AH, Fontana GA, Sovijarvi AR, et al; ERS Task Force. The diagnosis and management of chronic cough. Eur Respir J. 2004;24: 481-492.

6. Brignall K, Jayaraman B, Birring SS. Quality of life and psychosocial aspects of cough. Lung. 2008;186:S55-S58.

7. Irwin RS. Complications of cough: ACCP evidence-based clinical practice guidelines. Chest. 2006;129:54S-58S.

8. Dicpinigaitis PV, Tso R, Banauch G. Prevalence of depressive symptoms among patients with chronic cough. Chest. 2006;130:1839-1843.

9. McGarvey LPA, Carton C, Gamble LA, et al. Prevalence of psychomorbidity among patients with chronic cough. Cough. 2006;2:4.

10. Man WD, Hopkinson NS, Harraf F, et al. Abdominal muscle and quadriceps strength in chronic obstructive pulmonary disease. Thorax. 2005;60:718-722.

11. Ramírez-Sarmiento A, Orozco-Levi M, Barreiro E, et al. Expiratory muscle endurance in chronic obstructive pulmonary disease. Thorax. 2002;57:132-136.

12. Baghai-Ravary R, Quint JK, Goldring JJ, et al. Determinants and impact of fatigue in patients with chronic obstructive pulmonary disease. Respir Med. 2009;103:216-223.

13. Theander K, Hasselgren M, Luhr K, et al. Symptoms and impact of symptoms on function and health in patients with chronic obstructive pulmonary disease and chronic heart failure in primary health care. Int J Chron Obstruct Pulmon Dis. 2014;9:785-794.

14. Gift AG, Shepard CE. Fatigue and other symptoms in patients with chronic chronic obstructive pulmonary disease: do women and men differ? $J$ Obstet Gynecol Neonatal Nurs. 1999;28:201-208.

15. Polley L, Yaman N, Heaney L, et al. Impact of cough across different chronic respiratory diseases: comparison of two cough-specific healthrelated quality of life questionnaires. Chest. 2008;134:295-302. 
16. Calik-Kutukcu E, Savci S, Saglam M, et al. A comparison of muscle strength and endurance, exercise capacity, fatigue perception and quality of life in patients with chronic obstructive pulmonary disease and healthy subjects: a cross-sectional study. BMC Pulm Med. 2014;14:6.

17. Jette DU, Manago D, Medved E, et al. The disablement process in patients with pulmonary disease. Phys Ther. 1997;77:385-394.

18. Bestall JC, Paul EA, Garrod R, et al. Usefulness of the Medical Research Council (MRC) dyspnoea scale as a measure of disability in patients with chronic obstructive pulmonary disease. Thorax. 1999; 54:581-586.

19. Miller MR, Crapo R, Hankinson J, et al; ATS/ERS Task Force. General considerations for lung function testing. Eur Respir J. 2005;26: 153-161.

20. Pellegrino R, Viegi G, Brusasco V, et al; ATS/ERS Task Force. Interpretative strategies for lung function tests. Eur Respir J. 2005;26: 948-968.

21. Adams GM. Exercise Physiology Laboratory Manual. 1st ed. Dubuque, IA: Wm C Brown Publishers; 1990.

22. Kalpaklioglu AF, Kara T, Kurtipek E, et al. Evaluation and impact of chronic cough: comparison of specific vs generic quality-of-life questionnaires. Ann Allergy Asthma Immunol. 2005;94:581-585.

23. Berkhof FF, Boom LN, ten Hertog NE, et al. The validity and precision of the leicester cough questionnaire in COPD patients with chronic cough. Health Qual Life Outcomes. 2012;10:4.

24. Theander K, Cliffordson C, Torstensson O, Jakobsson P, Unosson M. Fatigue impact scale: its validation in patients with chronic obstructive pulmonary disease. Psychol Health Med. 2007;12:470-484.

25. Yilmaz N, Gencoz T, Ak M. Psychometric properties of the defense style questionnaire: a reliability and validity study. Turk Psikiyatri Derg. 2007;18:244-253.

26. Green SB, Salkind NJ. Using SPSS for Windows and Macintosh: Analyzing and Understanding Data. 5th ed. Upper Saddle River, NJ: Prentice Hall; 2008.

27. Domholdt E. Physical Therapy Research: Principles and Applications. 1st ed. Philadelphia: WB Saunders; 1993.

28. Tabachnick BG, Fidell LS. Using Multivariate Statistics. 6th ed. Boston: Pearson; 2013.

29. Irwin RS, French CT, Fletcher KE. Quality of life in coughers. Pulm Pharmacol Ther. 2002;15:282-286.

30. Morice AH, Fontana GA, Belvisi MG, et al; European Respiratory Society (ERS). ERS guidelines on the assessment of cough. Eur Respir J. 2007;29:1256-1276.

31. Widdicombe JG. A brief overview of the mechanisms of cough. In: Chung M, Widdicombe J, Boushey H, editors. Cough: Causes, Mechanisms and Therapy. United States of America: Blackwell Publishing; 2003:17-23.

32. Stephens RE, Addington WR, Miller SP, Anderson JW. Videofluoroscopy of the diaphragm during voluntary and reflex cough in humans. Am J Phys Med Rehabil. 2003;82:384.
33. Inal-Ince D, Savci S, Saglam M, et al. Fatigue and multidimensional disease severity in chronic obstructive pulmonary disease. Multidiscip Respir Med. 2010;5:162-167.

34. Lewko A, Bidgood PL, Garrod R. Evaluation of psychological and physiological predictors of fatigue in patients with COPD. BMC Pulm Med. 2009;9:47.

35. Kinsman RA, Yaroush RA, Fenandez E, et al. Symptoms and experience in chronic bronchitis and emphysema. Chest. 1983;83:755-761.

36. Wong CJ, Goodridge D, Marciniuk DD, Rennie D. Fatigue in patients with COPD participating in a pulmonary rehabilitation program. Int J Chron Obstruct Pulmon Dis. 2010;5:319-336.

37. Stridsman C, Müllerova H, Skär L, Lindberg A. Fatigue in COPD and the impact of respiratory symptoms and heart disease - a populationbased study. COPD. 2013;10:125-132.

38. Kapela MC, Larson JL, Patel MK, Covey MK, Berry JK. Subjective fatigue, influencing variables, and consequences in chronic obstructive pulmonary disease. Nurs Res. 2006;55:10-17.

39. Perera WR, Hurst JR, Wilkinson TM, et al. Inflammatory changes, recovery and recurrence at COPD exacerbation. Eur Respir J. 2007;29: $527 \mathrm{e} 34$.

40. Breslin E, van der Schans C, Breukink S, et al. Perception of fatigue and quality of life in patients with COPD. Chest. 1998;114: 958-964.

41. López-Campos JL. [Importance of fatigue, sleep quality and mood in patients with chronic obstructive pulmonary disease and the need for measurement instruments]. Arch Bronconeumol. 2009;45(Suppl 5): 2-6.

42. Negi H, Sarkar M, Raval AD, Pandey K, Das P. Presence of depression \& its risk factors in patients with chronic obstructive pulmonary disease. Indian J Med Res. 2014;139:402-408.

43. Blakemore A, Dickens C, Guthrie E, et al. Depression and anxiety predict health-related quality of life in chronic obstructive pulmonary disease: systematic review and meta-analysis. Int $J$ Chron Obstruct Pulmon Dis. 2014;9:501-512.

44. Irwin RS, French CL, Fletcher KE. The quality of life in coughers. In: Chung M, Widdicombe J, Boushey H, editors. Cough: Causes, Mechanisms and Therapy. United States of America: Blackwell Publishing; 2003:75-79.

45. Birring SS, Prudon B, Carr AJ, et al. Development of a symptom specific health status measure for patients with chronic cough: Leicester Cough Questionnaire (LCQ). Thorax. 2003;58:339-343.

46. Schmit KM, Coeytaux RR, Goode AP, et al. Evaluating cough assessment tools: a systematic review. Chest. 2013;144:1819-1826.

47. Chamberlain S, Birring SS, Garrod R. Nonpharmacological interventions for refractory chronic cough patients: systematic review. Lung. 2014; 192:75-85.
International Journal of COPD

\section{Publish your work in this journal}

The International Journal of COPD is an international, peer-reviewed journal of therapeutics and pharmacology focusing on concise rapid reporting of clinical studies and reviews in COPD. Special focus is given to the pathophysiological processes underlying the disease, intervention programs, patient focused education, and self management protocols.

\section{Dovepress}

This journal is indexed on PubMed Central, MedLine and CAS. The manuscript management system is completely online and includes a very quick and fair peer-review system, which is all easy to use. Visi http://www.dovepress.com/testimonials.php to read real quotes from published authors. 